\title{
In situ Detection of MicroRNAs: The Art of MicroRNA Research in Human Diseases
}

\author{
Duo Zhang ${ }^{1}$, Lixin $\mathrm{Xie}^{2}$ and Yang Jin ${ }^{1 *}$ \\ ${ }^{1}$ Division of Pulmonary and Critical Care Medicine, Brigham and Women's Hospital, Harvard Medical School, Boston, MA, USA 02115 \\ ${ }^{2}$ Department of Respiratory Medicine, Chinese PLA General Hospital, 28th Fuxing Road, Beijing 100853, PR China
}

"Corresponding author: Yang Jin, Division of Pulmonary and Critical Care, Department of Medicine, Brigham and Women's Hospital, Harvard Medical School, 75 Francis St., Boston, MA 02115, USA, Tel: 6177324334; E-mail: yjin@rics.bwh.harvard.edu

Rec date: Apr 27, 2015; Acc date: May 21, 2015; Pub date: May 23, 2015

Copyright: ( 2015 Zhang D, et al. This is an open-access article distributed under the terms of the Creative Commons Attribution License, which permits unrestricted use, distribution, and reproduction in any medium, provided the original author and source are credited.

\section{Keywords: MicroRNA (miRNA); FISH; In situ; Northern blot analysis}

Immunofluorescence; qPCR; Microarray

\section{Introduction}

MicroRNAs (miRNAs) are a class of evolutionally conserved small non-coding RNAs that serve as a post-transcriptional regulator of gene expression [1]. Since the discovery of first microRNA lin-4 [2], more than 1200 miRNAs have been identified in human genome. More than $30 \%$ of the coding genes are under the regulation of miRNAs [3]. It is therefore not surprising that miRNAs play critical roles in almost every biological process, such as cell proliferation, differentiation, apoptosis, and cell fate determination. Today, it is known that deregulation of miRNAs is associated with various human diseases, including cancer, metabolic diseases, cardiovascular disease and neurodegenerative disorders [4-7]. Emerging evidence show that miRNAs will be useful as biomarkers and molecular targets for novel therapy in human disease. Therefore, accurate detection, analysis and quantification of miRNAs are essential in those applications in which miRNAs are used as diagnostic or therapeutic targets. This minireview will discuss the current technology on miRNA detection and quantification.

\section{miRNA generation}

Most of the miRNA genes are transcribed by RNA polymerase II or III to form primary miRNAs (pri-miRNAs) [8]. In the nucleus, the pri-miRNAs are cleaved by microprocessor complex containing the RNase III enzyme Drosha and the double-stranded RNA-binding domain (dsRBD) protein DGCR8/Pasha to produce the precursor miRNAs (pre-miRNAs) [9]. Pre-miRNAs are 70 100 nucleotides in length with a stem-loop structure. Pre-miRNAs are subsequently transported into the cytoplasm by exportin 5 [10], where pre-miRNA hairpins can be further cleaved by another RNase III enzyme named Dicer [11]. After the double-stranded duplex is separated, the mature miRNA molecules incorporate into RNA-induced silencing complex (RISC), subsequently induce posttranscriptional gene silencing by translational inhibition or target mRNAs degradation [11] (Figure 1).

\section{Common Methods to Detect and Quantify miRNA}

For miRNA detections, conventional methods include Northern blot analysis, qRT-PCR, and microarray (Table 1).

Northern blot analysis is the earliest detecting method used to assess miRNA expression profiles [12]. To be noted, different forms of miRNA, including pri-miRNA, pre-miRNA and mature forms, all can be detected from total RNA without amplification. To date, the probe designing and labeling techniques have greatly improved for Northern blot analysis [13]. Although Northern blot analysis is recognized as a time- and sample-consuming method, it remains widely accepted as one of the reliable approaches for miRNAs determination.

\section{Quantitative PCR}

Currently, qPCR detection of miRNAs is the most widely used method. This technology is based on the reverse transcription which converts miRNAs to cDNAs. Two methods are often used for miRNA reverse transcription, including stem-loop RT primers and poly (A) tail addition methods $[14,15]$. In general, qPCR method is deemed as the major approach for miRNAs quantification.

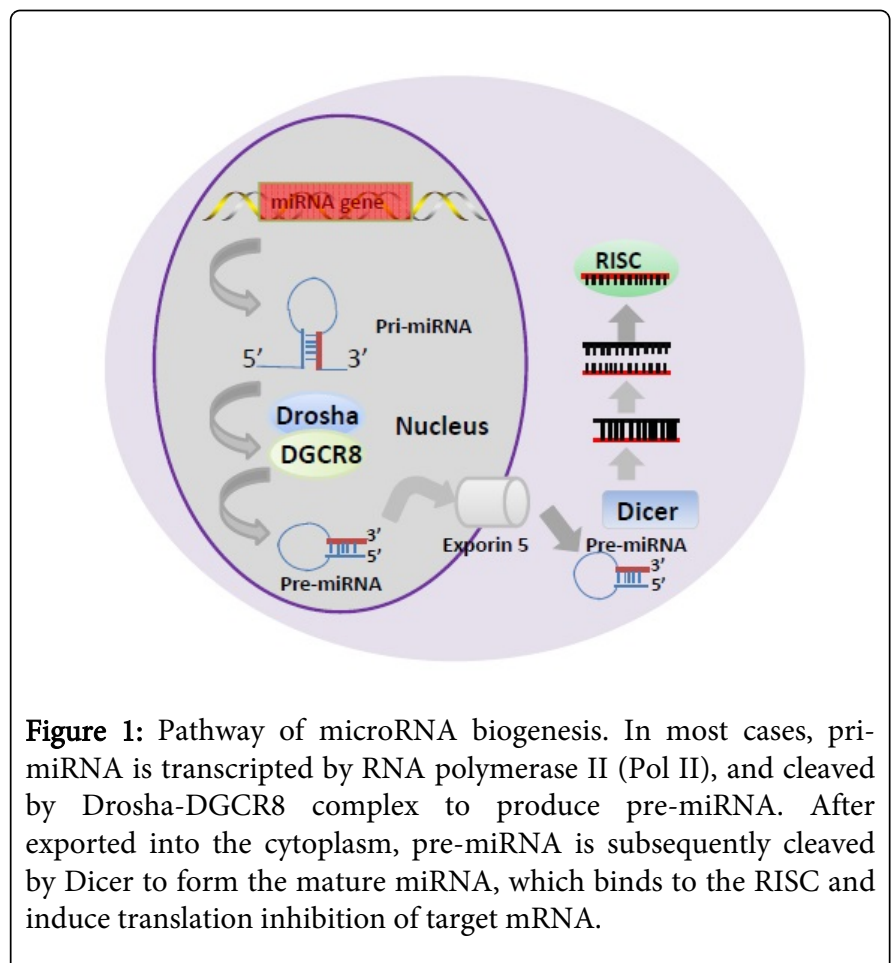


Page 2 of 3

\begin{tabular}{|l|l|l|}
\hline $\begin{array}{l}\text { miRNA detection } \\
\text { method }\end{array}$ & Advantages & Disadvantages \\
\hline Northern blotting & $\begin{array}{l}\text { Detection without amplification, all forms of miRNAs can be } \\
\text { detected. }\end{array}$ & $\begin{array}{l}\text { low-throughput, consuming time and large amount of RNA, hard } \\
\text { to detect miRNAs with low copy numbers }\end{array}$ \\
\hline qRT-PCR & $\begin{array}{l}\text { quick and easy to perform, relative low cost and small amounts } \\
\text { of sample consummation }\end{array}$ & $\begin{array}{l}\text { amplification needed, generation of non-specific amplification } \\
\text { products }\end{array}$ \\
\hline Microarray & high-throughput & $\begin{array}{l}\text { amplification needed, non-specific hybridization, not accurate and } \\
\text { need to be confirmed }\end{array}$ \\
\hline
\end{tabular}

Table 1: The advantages and disadvantages of common methods to detect and quantify miRNA

\section{miRNA microarray}

Microarray technology is a high-throughput method to provide essential information for miRNAs screening [16]. It is a powerful tool for the genome-wide analysis of miRNA expression. To increase accuracy of miRNAs quantification, new methods in miRNA labeling and probe design have been developed and used in miRNA microarray [17]. However, more accurate quantification technique is still to be explored.

\section{In situ Detection of miRNA}

The conventional methods of miRNA detection mentioned above are all indirect ways, in that the RNA from tissues or cells has to be first extracted before miRNA quantifications. As a result, these methods lose useful information about the spatial expression of miRNAs in tissue and cells. Evaluation of the spatial expression of miRNAs is especially crucial for those tissues with a number of different cell types. In 2004, in situ hybridization (ISH) technology was used for the first time in plants to assess miRNAs [18]. ISH technology is a direct and powerful technique to visualize the spatial localization of miRNAs at cellular level. Application of locked nucleic acid (LNA) probes in miRNA ISH has robustly improved the base-pairing specificity and stability of miRNA-mRNA complex [19]. Today, the ISH-based miRNA detection provides a reliable assessment of the physiologic function of miRNA at spatial location and the single-cell level [20]. For example, using fluorescence ISH system, the tumorspecific miRNAs miR-205 and miR-375 were respectively identified in two skin tumors, basal cell carcinoma (BCC) and Merkel cell carcinoma (MCC)[21]. Another published work showed that miR-21 is expressed in alveolar cells morphologically resembling alveolar type II cells in the normal lung and it is upregulated in cells surrounding fibrotic foci during lung fibrosis [22]. Therefore, in situ detection of miRNA not only demonstrates its expression, but also offers clues to possible functional roles.

\section{Current Methods to Detect miRNA In situ}

A variety of miRNA ISH protocols have been published, for both tissue sections and cultured cells [23-25]. Fixation using paraformaldehyde is needed in cultured cells and cryosections in order to prevent the loss of miRNA during hybridization. For the paraffin embedded-, formalin-fixed tissue, microRNA ISH requires several additional steps. These steps, such as deparaffination and predigestion, are used to enhance the binding affinity/specificity and optimize permeability before hybridization. The same steps are performed after pretreatment, including hybridization, washing, blocking and detection.
For current miRNA ISH, LNA ${ }^{\mathrm{mu}}$ probes have been the most accepted, because that the use of LNA $^{\text {ix }}$ efficiently increases the specificity in target detection [26]. In addition, appropriate labeling method for LNA-probes is important given that a variety of labeling choices are available for ISH detection. The techniques for probe modifications include the labels with fluorescence, biotin, digoxigenin (DIG), enzymes such as alkaline phosphatase (AP) and horseradish peroxidase (HRP), as well as radio isotopes [27-31]. The fluorescencelabeled probe is especially a useful technique known as fluorescent in situ hybridization (FISH). To be noted, fluorescence-based probe is not sensitive enough to detect the miRNAs with low copies. In the presence of substrate, the enzyme which is conjugated to the probes catalyzes substrate into colored products, which can be detected and quantified. Biotin-labeled system has been used for nucleic acid detection, given that it is stable and highly sensitive. However, endogenous biotin in tissues can cause high levels of background after hybridization. Currently, DIG label is the most popular, convenient, and effective one for miRNA ISH. Compared with the biotin one, DIG system has much lower background. AP conjugated DIG antibody is often used to bind to the LNATM probe (Figure 2). Although the radioactively labeled probes are less used today, they remain the most sensitive method which can be used to quantify miRNA ISH [32]. As mentioned above, LNA-based miRNA ISH is an essential technique which provides a unique method to locate and quantify miRNA expressions in tissue and cells. Traditional methods, such as Northern blot analysis, qPCR and microarray, fail to locate the miRNAs within tissue or cells.

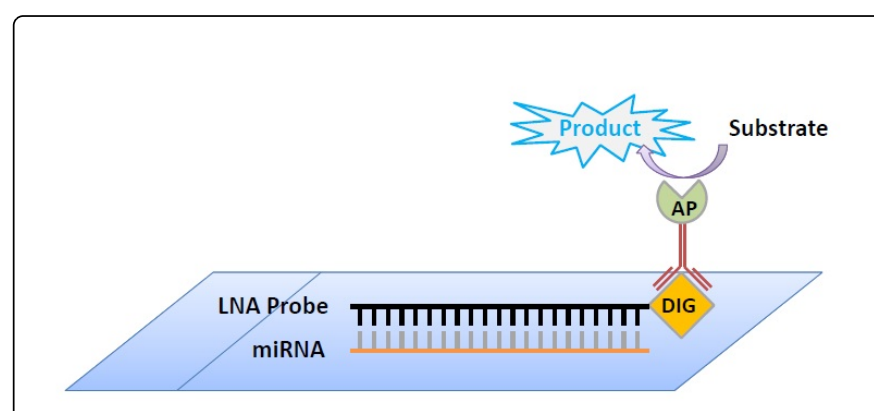

Figure 2: DIG-labeled in situ hybridization for microRNA detection (schematic presentation). DIG labeled LNA probe is used to bind and detect the specific miRNA based on the complementary basepairing. After hybridization and washing, AP-labeled antibody specifically recognizes the DIG labeled probe. When substrate is added, the signal represents the miRNA expression and can be visualized and quantified. 
However, miRNA ISH also has its own disadvantages. Strong background and absence of detecting signal are the major problems with miRNA ISH. An optimized miRNA ISH protocol with good signal-to-noise ratio is crucial. This optimizing process is often timeconsuming, given that the concentration of buffer, the duration and temperature of hybridization all have to be adjusted for each probe in order to acquire the most accurate data.

In summary, ISH-based miRNA detection is a powerful tool to detect and characterize miRNA location/expression in tissue and cells. It provides a direct method of analyzing spatial profile in formalinfixed paraffin embedded (FFPE) tissue and small biopsied specimens (cryosections). Along with the increasing knowledge of miRNAs, the histological analysis of their expression and location has been used in the development of diagnostic and therapeutic tools for human diseases, such as bladder cancer [33], thyroid nodules[25], Alzheimer's disease[34], and lung fibrosis[22]. miRNA ISH improves our understanding on this small molecule and its important role as biomarkers or therapeutic targets.

\section{Acknowledgement}

This work is supported by National Institutes of Health R01 HL102076 (Y.J.). R01 GM 111313 (Y.J.).

\section{References}

1. Mourelatos Z (2007) Small regulatory RNAs: biogenesis \& functions. Nucleic Acids Symp Ser (Oxf): 105.

2. Lee RC, Feinbaum RL, Ambros V (1993) The C. elegans heterochronic gene lin-4 encodes small RNAs with antisense complementarity to lin-14. Cell 75: 843-854.

3. Griffiths-Jones S, Saini HK, van Dongen S, Enright AJ (2008) miRBase: tools for microRNA genomics. Nucleic Acids Res 36: D154-158.

4. Oom AL, Humphries BA, Yang C (2014) MicroRNAs: novel players in cancer diagnosis and therapies. Biomed Res Int 2014: 959461.

5. Nishiguchi $T$, Imanishi $T$, Akasaka $T$ (2015) MicroRNAs and cardiovascular diseases. Biomed Res Int 2015: 682857.

6. Peng Y, Yu S, Li H, Xiang H, Peng J, et al. (2014) MicroRNAs: emerging roles in adipogenesis and obesity. Cell Signal 26: 1888-1896.

7. Maciotta S, Meregalli M, Torrente Y (2013) The involvement of microRNAs in neurodegenerative diseases. Front Cell Neurosci 7: 265.

8. Ying SY, Lin SL (2005) Intronic microRNAs. Biochem Biophys Res Commun 326: 515-520.

9. Kim VN, Han J, Siomi MC (2009) Biogenesis of small RNAs in animals Nat Rev Mol Cell Biol 10: 126-139.

10. Lund E, Güttinger S, Calado A, Dahlberg JE, Kutay U (2004) Nuclear export of microRNA precursors. Science 303: 95-98.

11. Ha M, Kim VN (2014) Regulation of microRNA biogenesis. Nat Rev Mol Cell Biol 15: 509-524.

12. Lagos-Quintana $M$, Rauhut $R$, Lendeckel $W$, Tuschl $T$ (2001) Identification of novel genes coding for small expressed RNAs. Science 294: 853-858.

13. Berezikov E, Cuppen E, Plasterk RH (2006) Approaches to microRNA discovery. Nat Genet 38 Suppl: S2-7.

14. Schmittgen TD, Lee EJ, Jiang J, Sarkar A, Yang L, et al. (2008) Real-time PCR quantification of precursor and mature microRNA. Methods 44: 31-38.

15. Chen C, Ridzon DA, Broomer AJ, Zhou Z, Lee DH, et al. (2005) Real-time quantification of microRNAs by stem-loop RT-PCR. Nucleic Acids Res 33: e179.

This article was originally published in a special issue, entitled:

"Cytopathology", Edited by Borislav A. Alexiev, University of Maryland Medical Center, USA
16. Yin JQ, Zhao RC, Morris KV (2008) Profiling microRNA expression with microarrays. Trends Biotechnol 26: 70-76.

17. Lee JM, Cho H, Jung Y (2010) Fabrication of a structure-specific RNA binder for array detection of label-free microRNA. Angew Chem Int Ed Engl 49: 8662-8665.

18. Chen X (2004) A microRNA as a translational repressor of APETALA2 in Arabidopsis flower development. Science 303: 2022-2025.

19. Kauppinen S, Vester B, Wengel J (2006) Locked nucleic acid: high-affinity targeting of complementary RNA for RNomics. Handb Exp Pharmacol: 405-422.

20. Dong H, Lei J, Ding L, Wen Y, Ju H, et al. (2013) MicroRNA: function, detection, and bioanalysis. Chem Rev 113: 6207-6233.

21. Renwick N, Cekan P, Masry PA, McGeary SE, Miller JB, et al. (2013) Multicolor microRNA FISH effectively differentiates tumor types. J Clin Invest 123: 2694-2702.

22. Yamada M, Kubo H, Ota C, Takahashi T, Tando Y, et al. (2013) The increase of microRNA-21 during lung fibrosis and its contribution to epithelial-mesenchymal transition in pulmonary epithelial cells. Respir Res 14: 95.

23. Song R, Ro S, Yan W (2010) In situ hybridization detection of microRNAs. Methods Mol Biol 629: 287-294.

24. Ugras S, Brill E, Jacobsen A, Hafner M, Socci ND, et al. (2011) Small RNA sequencing and functional characterization reveals MicroRNA-143 tumor suppressor activity in liposarcoma. Cancer Res 71: 5659-5669.

25. Guo Z, Hardin H, Montemayor-Garcia C, Asioli S, Righi A, et al. (2015) In Situ Hybridization Analysis of miR-146b-5p and miR-21 in Thyroid Nodules: Diagnostic Implications. Endocr Pathol 26: 157-163.

26. Nuovo GJ (2010) In situ detection of microRNAs in paraffin embedded, formalin fixed tissues and the co-localization of their putative targets. Methods 52: 307-315.

27. Kloosterman WP, Wienholds E, de Bruijn E, Kauppinen S, Plasterk RH (2006) In situ detection of miRNAs in animal embryos using LNAmodified oligonucleotide probes. Nat Methods 3: 27-29.

28. Silahtaroglu AN, Nolting D, Dyrskjøt L, Berezikov E, Møller M, et al. (2007) Detection of microRNAs in frozen tissue sections by fluorescence in situ hybridization using locked nucleic acid probes and tyramide signal amplification. Nat Protoc 2: 2520-2528.

29. Elkan-Miller T, Ulitsky I, Hertzano R, Rudnicki A, Dror AA, et al. (2011) Integration of transcriptomics, proteomics, and microRNA analyses reveals novel microRNA regulation of targets in the mammalian inner ear. PLoS One 6: e18195.

30. Shi Z, Johnson JJ, Stack MS (2012) Fluorescence In Situ Hybridization for MicroRNA Detection in Archived Oral Cancer Tissues. J Oncol 2012: 903581.

31. Sempere LF, Korc M (2013) A method for conducting highly sensitive microRNA in situ hybridization and immunohistochemical analysis in pancreatic cancer. Methods Mol Biol 980: 43-59.

32. Thompson RC, Deo M, Turner DL (2007) Analysis of microRNA expression by in situ hybridization with RNA oligonucleotide probes. Methods 43: 153-161.

33. Andrew AS, Marsit CJ, Schned AR, Seigne JD, Kelsey KT, et al. (2014) Expression of tumor suppressive microRNA-34a is associated with a reduced risk of bladder cancer recurrence. Int J Cancer .

34. Nelson PT, Wilfred BR (2009) In situ hybridization is a necessary experimental complement to microRNA (miRNA) expression profiling in the human brain. Neurosci Lett 466: 69-72. 